\title{
Effects of inactivated and live cells of Saccharomyces cerevisiae on in vitro ruminal fermentation of diets with different forage: concentrate ratio
}

\author{
F. OPSI ${ }^{1}$, R. FORTINA ${ }^{1}$, S. TASSONE ${ }^{1}$, R. BODAS ${ }^{2}$ AND S. LÓPEZ ${ }^{2,3}$ \\ ${ }^{1}$ Dipartimento di Scienze Zootecniche, Università degli Studi di Torino, I-10095 Grugliasco (Torino), Italy \\ 2 Instituto de Ganadería de Montaña (CSIC-ULE), E-24346 Grulleros (León), Spain \\ ${ }^{3}$ Departamento de Producción Animal, Universidad de León, E-24071 León, Spain
}

(Received 23 February 2011; revised 4 April 2011; accepted 11 April 2011; first published online 7 July 2011)

\section{SUMMARY}

The effects of yeast Saccharomyces cerevisiae, either inactivated (by osmotic pressure, designated IY) or provided as a culture containing live yeast cells (YC), on ruminal fermentation of two different diets were investigated in vitro. Total mixed rations (TMR) having forage:concentrate ratios of 0.6:0.4 (medium-high forage diet) and 0.2:0·8 (low-forage diet) were incubated in batch cultures of mixed ruminal micro-organisms to which either IY (to reach concentrations of 500 and $250 \mathrm{mg}$ product/l incubation medium) or YC (at a concentration of $150 \mathrm{mg}$ product/l) were added directly as powder. To evaluate the effects of the additive on ruminal microbial population, sheep used as donors of rumen fluid were allocated to three experimental groups: Control (no additive), IY and YC, that received a diet with the corresponding additive for 10 days. With both diets, $Y C$ decreased ruminal $\mathrm{pH}$ compared to control, whereas IY had no effect. Adding yeast products to the high-fibre diet affected total volatile fatty acid (VFA) production and VFA composition, in general with a slight increase in IY and a significantly greater increase in response to the addition of YC. Ammonia nitrogen $(P=0 \cdot 006)$, total gas production $(P<0 \cdot 001)$ and in vitro dry matter disappearance (IVD) $(P<0.001)$ showed the highest values with YC. Methane production was higher than the control when the IY inoculum was used, and increased even more with the YC inoculum $(P<0 \cdot 001)$. With the high-concentrate TMR, no effects on total VFA concentration were observed when yeast additives were used. Similar trends were shown for lactate and methane production and total gas production, where values tended to be higher when using the $Y C$ inoculum ( $P$ values of 0.055, $<0.001,0.006$ and $<0.001$, respectively). After $144 \mathrm{~h}$ of incubation, differences were observed only with the high-fibre diet in the cumulative gas production at $24 \mathrm{~h}$ of incubation and in the average fermentation rate, which was greater with $\mathrm{YC}$, although the asymptotic gas production was not affected. These results indicate that live yeasts affect ruminal fermentation slightly more than inactivated yeasts, although both products require a regular administration and some adaptation of the ruminal microbial population for the stimulatory effects to become apparent. The effects of yeasts on ruminal fermentation are diet-dependent, being more noticeable with a high-fibre substrate, and subtle with a highconcentrate diet.

\section{INTRODUCTION}

A yeast culture is a fermented feed additive that can contain either live or inactivated yeast cells, the culture medium on which the yeast was grown and the metabolic by-products produced by yeast during fermentation (Linn \& Raeth-Knight 2006). The most common yeast additive used in ruminant diets is obtained from

* To whom all correspondence should be addressed. Email: raul. bodas@eae.csic.es cultures of Saccharomyces cerevisiae. This additive has been used for many years to enhance ruminal fermentation, reducing energy and nutrient losses and thus improving production efficiency in ruminant production systems. In recent years, with increased consumer concern about safety, quality of animal products and environmental impact, antibiotics and synthetic chemical products have been banned as feed additives by the European Union (Anadón 2006). Alternative additives such as yeasts are used not only to increase 
productivity but also to decrease the risk of transfer of antibiotic resistance or potential human pathogens and to limit excretion of pollutants (ChaucheyrasDurand et al. 2008).

Some experiments have shown that yeast additives may improve feed intake and milk production in dairy cattle (Harris \& Webb 1990; Williams et al. 1991; Piva et al. 1993; Kung et al. 1997; Dann et al. 2000; Nocek et al. 2003). These responses are usually related to stimulation of cellulolytic bacteria (Newbold et al. 1996) enhancing potential fibre digestion in the rumen, and to their potential to prevent a fall in rumen $\mathrm{pH}$ by decreasing lactic acid production and/or increasing utilization of lactic acid by some bacteria (Chaucheyras-Durand et al. 1996; Callaway \& Martin 1997). Yeasts also affect feed degradability, and the patterns of volatile fatty acid (VFA) production (Carro et al. 1992; Zeleňák et al. 1994; Guedes et al. 2008). However, yeast responses are not always consistent (Arcos-García et al. 2000). Some authors, in fact, have observed that milk yield, milk composition, body weight gain and feed intake were not affected by the addition of $S$. cerevisiae to the diet (Chiquette 1995; Kamalamma et al. 1996), with no noticeable effects of this yeast on bacterial counts or bacterial colonization of roughage in the rumen (Chiquette 1995). Some of the possible causes for the inconsistency could be associated with the characteristics of different yeast strains, the amount of added yeast (Mendoza et al. 1995; Newbold et al. 1995), type of animals and diet composition (Carro et al. 1992; Wallace 1994; Zeleňák et al. 1994).

Most of the above-mentioned in vivo and in vitro research with yeast products has been conducted with $S$. cerevisiae cultures that include the yeast and the medium on which it was grown, along with components such as vitamins and other fermentation products, potentially able to stabilize the rumen environment. Over the last few years, attention has turned towards discriminating between the effects of culture products and live yeast cells (YC) on ruminal fermentation, which are processed to remove the culture medium and to maintain a high live-cell count (Lynch \& Martin 2002). Some reports indicate that YC do not grow in the rumen but show some degree of viability (Dawson et al. 1990; Hession et al. 1992) and influence the course of rumen fermentation through interactions with ruminal micro-organisms (Harrison et al. 1988; Martin et al. 1989; Wallace \& Newbold 1993). The main effects that have been identified are improvement of the rumen environment favouring microbial establishment, stabilization of ruminal $\mathrm{pH}$ and interactions with lactate-metabolizing bacteria and increase of fibre degradation and interaction with plant-cell-wall degrading micro-organisms (Chaucheyras-Durand et al. 2008).

In addition to live cells, recent research and development have provided inactivated cells of $S$. cerevisiae with potential use as alternative yeast derivatives. According to the manufacturers, these products can supply more benefits and advantages compared to live cells. Even though the mechanism of action of inactivated yeast extracts (IY) could be similar in part to those of live cells, they ensure a uniformity of action and a faster or even immediate availability of the substances contained within the cells (vitamins or other growth factors) to autochthonous microbiota. However, experimental data regarding the use of this product are scarce (Piva et al. 1993; Mimosi et al. 2008; Fortina et al. 2009).

The objective of the current study was, therefore, to investigate and compare the effects of inactivated cells of $S$. cerevisiae and a yeast culture with live cells of S. cerevisiae on in vitro ruminal fermentation of diets with different forage:concentrate ratio.

\section{MATERIALS AND METHODS}

\section{Experimental design}

The additives tested were an IY of $S$. cerevisiae (Thepax $100 \mathrm{R}$, with declared composition of $5 \times 10^{9}$ inactivated cells/g of strain GSH351; Dox-Al Italia SpA, Sulbiate, Italy) and an extensively used additive with YC of S. cerevisiae (Yea-Sacc ${ }^{1026}$, a yeast culture with declared concentration of $10^{9} \mathrm{CFU} / \mathrm{g}$ of strain CBS 493.94; Alltech Inc., Ireland). The procedure of inactivation of Thepax $100 \mathrm{R}$ was based on changes in osmotic pressure, so the cells were dehydrated and rehydrated again, leaving the external membrane of the micro-organism unaltered (European Patent EP0904701A2).

The experiment was carried out to evaluate two different doses of inactivated yeast (to reach concentrations of 250 (IY250) or 500 (IY500) mg product per litre of incubation medium) tested against the live yeast (at a concentration of $150 \mathrm{mg}$ product/l, additive treatment $\mathrm{YC}$ ), each of which were added directly as powder to in vitro batch cultures of mixed ruminal micro-organisms (direct additive treatment $(T)$ effect). To evaluate the effects of the additive on ruminal microbial population, 12 rumen-fistulated Assaf sheep 
were assigned randomly to the following treatments (four sheep per group): control group (no additive), IY group (receiving $3.5 \mathrm{~g}$ Thepax $100 \mathrm{R} / \mathrm{animal} /$ day) and YC group (receiving $1.5 \mathrm{~g}$ Yea-Sacc ${ }^{1026} /$ animal/day). Additives were dosed intraruminally through the cannula once daily at $08.00 \mathrm{~h}$ for 10 days before starting the in vitro assay to test the effects of the additives on the fermentative activity of the rumen fluid used as inoculum in the in vitro trials (adapted rumen fluid or inoculum ( $I$ ) effect). Sheep were fed ad libitum a diet consisting of alfalfa hay with free access to fresh water during the adaptation period of 10 days. Animal handling followed the recommendations of European Council Directive 86/609/EEC for protection of animals used for experimental and other scientific purposes (CEC 1986), and experimental procedures were approved by the University of León (Spain) Institutional Animal Care and Use Committee.

Two total mixed ratios (TMR) of the following forage: concentrate ratios (DM basis): 0.6:0.4 (high-forage TMR) and 0.2:0·8 (high-concentrate TMR) were used to be incubated in vitro. Composition and chemical characteristics of diets are reported in Table 1.

\section{In vitro experiments}

Ruminal contents were collected individually from each donor sheep in thermos flasks before the morning feeding and taken to the laboratory, where ruminal contents from each sheep were strained through two layers of cheesecloth and kept at $39{ }^{\circ} \mathrm{C}$ under a $\mathrm{CO}_{2}$ atmosphere.

\section{In vitro gas production}

In vitro gas production measurements were conducted using a pressure transducer as described by Theodorou et al. (1994). Samples of the diet to be incubated $(500 \pm 10 \mathrm{mg})$ were weighed out in $120 \mathrm{ml}$ serum bottles to which $50 \mathrm{ml}$ of diluted rumen fluid were dispensed. Rumen fluid was previously diluted (1:4, $\mathrm{v} / \mathrm{v}$ ) with a culture medium containing macro- and micro-mineral solutions, a bicarbonate buffer solution and resazurin, prepared as described by Menke \& Steingass (1988). The medium was maintained at $39^{\circ} \mathrm{C}$ and saturated with $\mathrm{CO}_{2}$; oxygen was reduced by the addition of a solution containing cysteine hydrochloride and sodium sulphide. Blanks (bottles without samples) were used to compensate for gas production in the absence of substrate. Once filled, bottles were sealed with rubber stoppers and aluminium seals, shaken and placed in the incubator at $39^{\circ} \mathrm{C}$. The
Table 1. Composition and nutrient content ( $\mathrm{g} / \mathrm{kg}$ DM) of experimental TMR

\begin{tabular}{lcc}
\hline \hline & $\begin{array}{c}\text { High- } \\
\text { forage } \\
\text { TMR }\end{array}$ & $\begin{array}{l}\text { High- } \\
\text { concentrate } \\
\text { TMR }\end{array}$ \\
& & \\
& 423 & 250 \\
Ingredient & 221 & 200 \\
Maize silage & 179 & 200 \\
Maize meal & 141 & 163 \\
Soybean meal & 17 & 90 \\
Ryegrass hay & 12 & 65 \\
Minerals and vitamins* & 7 & 15 \\
Buffer saltt & & $8 \cdot 2$ \\
Sodium bicarbonate & & 4 \\
Calcium carbonate & & $1 \cdot 8$ \\
Sodium chloride & & $1 \cdot 7$ \\
Wheat bran & & $1 \cdot 3$ \\
Dicalcium phosphate & & \\
Calcium soap (blend) & 91 & 892 \\
Nutrient & 101 \\
DM, as fed & 35 & 187 \\
Ash & 26 & 26 \\
CP & 416 & 254 \\
EE & & 156 \\
NDF & & 21 \\
ADF & & \\
Lignin & & \\
\hline \hline
\end{tabular}

* Containing (per g): Beta carotene, 0.12 mg; vitamin A, $4000 \mathrm{IU}$; vitamin $\mathrm{D}_{3}, 500 \mathrm{IU}$; vitamin $\mathrm{E}, 1 \mathrm{mg}$; vitamin $\mathrm{B}_{1}$, $0.014 \mathrm{mg}$; vitamin $\mathrm{B}_{2}, 0.015 \mathrm{mg}$; vitamin $\mathrm{B}_{6}, 0.003 \mathrm{mg}$; vitamin $B_{12}, 0.01 \mathrm{mg}$; vitamin $C, 7 \mathrm{mg}$; biotin, $0.0015 \mathrm{mg}$; choline, $2.5 \mathrm{mg} ; \mathrm{Zn}, 20 \mathrm{mg} ; \mathrm{Mn}, 12 \mathrm{mg}$; Fe, $5 \mathrm{mg}$; $\mathrm{Cu}$, $2.5 \mathrm{mg}$; I, $0.5 \mathrm{mg}$; Co, $0.2 \mathrm{mg}$; Se, $0.04 \mathrm{mg}$.

+ Containing (per g) : Ca, 200 mg; Na, 280 mg; Mg, 70 mg.

head-space gas pressure released upon fermentation of feed was measured using a pressure transducer at $3,6,9,12,16,21,26,31,36,48,60,72,96,120$ and $144 \mathrm{~h}$ after inoculation time. Incubations were performed in two batches, carried out in two consecutive weeks with different sources of inocula. Within each batch, 48 vials were incubated per substrate corresponding to three inocula (control, IY and $Y C$ ) $\times$ two sheep per inoculum $\times$ four additive treatments (control, IY250, IY500 and YC) $\times$ two serum bottles (duplicates). Gas volume was estimated from pressure measurements using the equation proposed by López et al. (2007). In order to estimate the fermentation kinetics parameters, gas production data were fitted to the exponential model proposed by France et al. (2000):

$G=A\left[1-e^{-c(t-L)}\right]$

where $G(\mathrm{ml} / \mathrm{g} \mathrm{DM})$ is the cumulative gas production at time $t ; A(\mathrm{ml} / \mathrm{g} \mathrm{DM})$ is the asymptotic gas 
production; e is Napier's constant; c (/h) is the fractional rate of fermentation and $L(\mathrm{~h})$ is the lag time.

The average fermentation rate $(R, \mathrm{ml}$ gas $/ \mathrm{h})$ was defined as the average gas-production rate between the start of the incubation and the time at which the cumulative gas production was half of its asymptotic value, and was calculated as

$R=A c /[2(\ln 2+C L)]$

Volume of gas (ml/g DM) produced after $24 \mathrm{~h}$ of incubation (G24) was used as an index of digestibility and energy feed value, as suggested by Menke \& Steingass (1988).

In vitro $24 \mathrm{~h}$ incubations

Samples $(500 \pm 10 \mathrm{mg}$ ) of TMR (high forage and high concentrate) were incubated in serum bottles with diluted rumen fluid in a culture medium as described in the previous paragraph. Incubations were performed in two batches carried out in two consecutive weeks with different sources of inocula. Within each batch, 48 vials were incubated per substrate, corresponding to three inocula (control, IY and YC) $\times$ two sheep per inoculum $\times$ four additive treatments (control, IY250, IY500 and YC) $\times$ two serum bottles (duplicates). At $24 \mathrm{~h}$ of incubation, gas pressure and volume were recorded using a pressure transducer and a graduated syringe, and a gas sample $(10 \mathrm{ml})$ was taken from each bottle and kept in vacuum tubes (Venoject ${ }^{\circledR}$, Terumo Europe N.V., Belgium) until being analysed for methane $\left(\mathrm{CH}_{4}\right)$. Fermentation was stopped immediately by swirling the bottles in ice; the bottles were opened, $\mathrm{pH}$ measured (using a $\mathrm{pH}$-meter) and samples of supernatant were taken for determination of ammonia, lactate and VFA. Finally, the contents of each serum bottle were filtered using sintered glass crucibles (pore size No. 1) under a vacuum and oven-dried at $100{ }^{\circ} \mathrm{C}$ for $48 \mathrm{~h}$ to estimate the disappearance of dry matter (IVD) at $24 \mathrm{~h}$ of incubation. Methane was determined by gas chromatography. The volume of methane $(M, \mathrm{ml})$ produced at the end of incubation was calculated from the volume of gas and the gas composition data, as proposed by López et al. (2007):

$M=(G+V h) C$

where $G$ is the volume $(\mathrm{ml})$ of total gas produced at the end of incubation $(24 \mathrm{~h}), V h$ is the volume $(\mathrm{ml})$ of the headspace in the serum bottle and $C$ is the proportion of methane in the analysed sample. Samples of diluted rumen fluid, collected at $0 \mathrm{~h}$ (before incubation started) and $24 \mathrm{~h}$ of incubation, were processed. A $2 \mathrm{ml}$ aliquot was acidified with $2 \mathrm{ml}$ of 0.5 normal hydrochloric acid $(\mathrm{HCl})$ for ammonia- $\mathrm{N}\left(\mathrm{NH}_{3}-\mathrm{N}\right)$ and lactic acid determination and a $0.8 \mathrm{ml}$ sample of the supernatant was added to $0.5 \mathrm{ml}$ of a deproteinizing solution $(5 \mathrm{~g}$ metaphosphoric acid and $1 \mathrm{~g}$ crotonic acid in $250 \mathrm{ml}$ of $0.5 \mathrm{~N} \mathrm{HCl}$ ) for VFA determination. Both samples were centrifuged at $14500 \mathrm{~g}$ for $15 \mathrm{~min}$ at $4{ }^{\circ} \mathrm{C}$, and supernatants were collected for subsequent analysis. $\mathrm{NH}_{3}-\mathrm{N}$ concentration was determined as described by Weatherburn (1967), VFA contents were determined by gas chromatography using crotonic acid as internal standard (Ottenstein \& Bartley 1971) and lactate was determined using a colorimetric assay as described by Taylor (1996).

In vitro digestibility

In vitro dry matter digestibility (IVDMD) of TMR samples was determined using the Ankom-Daisy procedure described by Robinson et al. (1999). Rumen fluid, obtained as described above, was diluted $(1: 4, v / v)$ into the medium as reported by Menke \& Steingass (1988). Two incubations were completed with one jar per inocula (control, IY and YC) in each incubation, each of which was added with respective treatment where necessary (control without addition, IY and YC) to reach the optimal concentrations of $500 \mathrm{mg}$ inactivated yeast product per litre incubation medium and $150 \mathrm{mg} / \mathrm{l}$ for live yeast adapted inocula. Samples of diets $(250 \pm 10 \mathrm{mg})$ were weighed in F57 Ankom bags with a pore size of $25 \mu \mathrm{m}$, heat-sealed and then placed into an incubation jar. Nine bags per substrate were used, corresponding to three treatments (control, IY, YC) $\times$ three replications. Each jar was a 5 litre glass recipient with a plastic lid provided with a one-way valve that avoids the accumulation of fermentation gases, filled with 2 litres of buffered rumen fluid under anaerobiosis and placed into the Daisyll Incubator (Ankom Technology Corp., Fairport, NY, USA). Temperature $\left(39^{\circ} \mathrm{C}\right)$ and constant levels of agitation were maintained in the controlled chamber with continuous rotation. After $48 \mathrm{~h}$ of incubation the jars were emptied and the bags were gently rinsed and dried in an oven at $60^{\circ} \mathrm{C}$. Bags were then washed in the fibre analyser with a neutral detergent solution at $100{ }^{\circ} \mathrm{C}$ for $1 \mathrm{~h}$ and rinsed with distilled water, so as to remove bacterial cell walls and other endogenous products. In vitro neutral detergent fibre digestibility (IVNDFD) was estimated from the amount of neutral detergent fibre (NDF) incubated. 


\section{Chemical analysis}

Samples of feed were oven dried at $60^{\circ} \mathrm{C}$ for $48 \mathrm{~h}$, then ground in a Buhler mill to pass through a $1 \mathrm{~mm}$ screen and assayed in duplicate according to the AOAC (2000) methods for DM (method 934.01), ash (method 942.05), crude protein (CP, method 954.01) and ether extract (EE, method 920.39). NDF, acid detergent fibre (ADF) and lignin were determined with the Ankom fibre analyser (Ankom Technology Corp. 1997), following the procedure of Van Soest et al. (1991). NDF was analysed using a heat-stable amylase and with the addition of sodium sulphite, and expressed exclusive of residual ash.

\section{Statistical analysis}

Data for each type of diet were subjected to ANOVA using the general linear model (GLM) of SPSS ( $v$ 17.0, SPSS Inc., Chicago, Illinois, USA). Separate analyses were performed for each TMR used in the incubations. The statistical model used for gas production kinetics and in vitro $24 \mathrm{~h}$ fermentation data included the fixed effects of inocula ( $/$ effects, with levels Control, IY and YC), treatments ( $T$ effects, with levels Control, IY250, IY500 and YC) and their interaction, and random effects of donor sheep within each inoculum. In vitro digestibility data were analysed by one-way ANOVA with the fixed effect of additive treatment ( $T$ effects, with levels Control, IY and YC) as the only source of variation. The standard error of difference and the number of observations (or replicates) for each experimental treatment within each source of variation are reported in the Tables.

\section{RESULTS}

Fermentation parameters at $24 \mathrm{~h}$ of incubation

The results of the influence of different yeast cell supplements on in vitro fermentation parameters at $24 \mathrm{~h}$ of incubation for high-forage TMR are given in Table 2. Different adapted inocula $(I)$ tested in the experiment affected some parameters, whereas treatments $(T)$ added to the batch of fermentation and the interaction $(I \times T)$ showed no significant effect $(P>0 \cdot 05)$. Ruminal $\mathrm{pH}$ was similar in control and IY inocula, but values were lower $(P=0 \cdot 008)$ with the YC inoculum. With the inoculum from sheep feeding the YC supplement, higher $\mathrm{NH}_{3}-\mathrm{N}(P=0.006)$, total gas production $(P<0.001)$ and in vitro dry matter disappearance (IVD, $P<0.001$ ) were observed.
Methane production (mmol/g DM incubated) was higher with IY inoculum, and increased even more with the YC inoculum $(P<0 \cdot 001)$. When expressed on degraded substrate basis, the highest values of methane production ( $\mathrm{mmol} / \mathrm{g}$ DM digested) were observed for IY inoculum $(P=0 \cdot 007)$. Incubation in rumen fluid from sheep supplemented with YC led to increased total VFA production $(P<0 \cdot 001)$, and similar trends were shown for acetate $(P<0 \cdot 001)$, butyrate $(P=0.020)$, valerate $(P=0.002)$ and iso-acids $(P=0.006)$ outputs, whereas the acetate:propionate ratio was increased with IY inoculum $(P=0 \cdot 001)$. The production of propionate decreased in IY, but increased in $Y C$ inoculum $(P<0 \cdot 001)$. The molar proportions of individual VFAs were affected by yeast products, so that acetate decreased and valerate increased in the YC inoculum $(P=0.046$ and 0.039, respectively), whereas acetate increased $(P=0 \cdot 046)$ and propionate decreased $(P=0 \cdot 004)$ with IY inoculum. Table 3 shows the effects of different yeast cell products on in vitro fermentation when the highconcentrate TMR was incubated. Significant differences were seen for adapted inocula only, whereas treatment $(T)$ and interaction $I \times T$ showed no significant differences. Similar trends were shown for lactate and methane production (either per g of DM incubated or DM digested) and total gas production, where values were higher when the high-concentrate TMR was incubated with YC inoculum ( $P$ values of 0.055 , $<0.001,0.006$ and $<0.001$, respectively). The $\mathrm{pH}$ showed an opposite trend, decreasing with the YC inoculum $(P=0 \cdot 033)$. In general, VFA production was not affected by the effects tested, with only propionate production being decreased slightly with IY and slightly increased with $Y C$ inoculum $(P=0 \cdot 003)$.

In vitro parameters of gas production kinetics and digestibility

The effect of $S$. cerevisiae on in vitro gas production kinetic parameters at $144 \mathrm{~h}$ of incubation for the TMR, are presented in Table 4 . The $A, c$ and $L$ parameters of high-forage diet showed no statistically significant differences due to inocula used in the experiment, to the treatment or to the $I \times T$ interaction. The $Y C$ inoculum gave rise to a significantly $(P=0 \cdot 010)$ higher cumulative gas production at $24 \mathrm{~h}$ of incubation $(P=0.010)$ and average fermentation rate $(P=0.014)$ than control and IY inocula, whereas $T$ and $T \times I$ interaction effects were not significant $(P>0 \cdot 05)$. In the high-concentrate TMR, none of the fermentation 
Table 2. Influence of different S. cerevisiae products (inactivated yeast extract, IY; live yeast cells, YC; IY at 250 and 500 mg product per litre of incubation medium, IY250 and IY500, respectively) on in vitro fermentation of high-forage TMR (24 h, DM basis)

\begin{tabular}{|c|c|c|c|c|c|c|c|c|c|c|c|c|}
\hline & \multicolumn{3}{|c|}{ Inoculum $n=8$} & \multirow[b]{2}{*}{ S.E.D. } & \multirow[b]{2}{*}{$P$ value $I$} & \multicolumn{4}{|c|}{ Treatment $n=6$} & \multirow[b]{2}{*}{ S.E.D. } & \multirow[b]{2}{*}{$P$ value $T$} & \multirow[b]{2}{*}{$P$ value $I \times T$} \\
\hline & Control & IY & YC & & & Control & IY250 & IY500 & YC & & & \\
\hline $\mathrm{pH}$ & $6 \cdot 65$ & $6 \cdot 66$ & $6 \cdot 61$ & $0 \cdot 016$ & $0 \cdot 008$ & $6 \cdot 64$ & $6 \cdot 64$ & $6 \cdot 64$ & $6 \cdot 64$ & $0 \cdot 018$ & NS & NS \\
\hline IVD (g/g) & $0 \cdot 61$ & $0 \cdot 62$ & $0 \cdot 73$ & $0 \cdot 016$ & $<0 \cdot 001$ & $0 \cdot 65$ & $0 \cdot 66$ & 0.65 & 0.65 & $0 \cdot 018$ & NS & NS \\
\hline Total gas (ml/g) & 143 & 153 & 182 & $4 \cdot 5$ & $<0 \cdot 001$ & 155 & 157 & 163 & 161 & $5 \cdot 1$ & NS & NS \\
\hline $\mathrm{CH}_{4}(\mathrm{mM} / \mathrm{g} \mathrm{DM}$ incubated $)$ & $1 \cdot 4$ & $1 \cdot 7$ & $1 \cdot 8$ & $0 \cdot 04$ & $<0 \cdot 001$ & $1 \cdot 6$ & $1 \cdot 6$ & $1 \cdot 7$ & $1 \cdot 6$ & $0 \cdot 04$ & NS & NS \\
\hline $\mathrm{CH}_{4}(\mathrm{mM} / \mathrm{g} \mathrm{DM}$ digested $)$ & $2 \cdot 4$ & $2 \cdot 7$ & $2 \cdot 5$ & $0 \cdot 08$ & $0 \cdot 007$ & $2 \cdot 5$ & $2 \cdot 5$ & $2 \cdot 6$ & $2 \cdot 5$ & $0 \cdot 09$ & NS & NS \\
\hline $\mathrm{CH}_{4}(\mathrm{mM} / \mathrm{M}$ gas $)$ & 233 & 241 & 227 & $9 \cdot 6$ & NS & 232 & 244 & 230 & 231 & $11 \cdot 0$ & NS & NS \\
\hline $\mathrm{NH}_{3}-\mathrm{N}(\mathrm{mg} / \mathrm{l})$ & 276 & 261 & 339 & $20 \cdot 2$ & $0 \cdot 006$ & 280 & 296 & 304 & 288 & $23 \cdot 3$ & NS & NS \\
\hline L-lactate (mg/l) & $10 \cdot 8$ & $11 \cdot 2$ & $11 \cdot 4$ & 0.91 & NS & $10 \cdot 0$ & $11 \cdot 2$ & $11 \cdot 2$ & $12 \cdot 1$ & $1 \cdot 05$ & NS & NS \\
\hline \multicolumn{13}{|l|}{ VFA (mM/g) } \\
\hline Acetate & $2 \cdot 80$ & $2 \cdot 94$ & $3 \cdot 39$ & $0 \cdot 104$ & $<0 \cdot 001$ & $2 \cdot 96$ & $3 \cdot 13$ & $3 \cdot 06$ & $3 \cdot 02$ & $0 \cdot 120$ & NS & NS \\
\hline Propionate & $1 \cdot 12$ & $0 \cdot 96$ & $1 \cdot 26$ & $0 \cdot 016$ & $<0 \cdot 001$ & $1 \cdot 08$ & $1 \cdot 14$ & $1 \cdot 12$ & $1 \cdot 12$ & $0 \cdot 018$ & NS & NS \\
\hline Butyrate & $0 \cdot 50$ & $0 \cdot 58$ & $0 \cdot 69$ & $0 \cdot 055$ & $0 \cdot 020$ & $0 \cdot 57$ & $0 \cdot 61$ & $0 \cdot 60$ & $0 \cdot 59$ & $0 \cdot 063$ & NS & NS \\
\hline \multirow[t]{2}{*}{ Valerate } & $0 \cdot 06$ & $0 \cdot 07$ & $0 \cdot 09$ & $0 \cdot 006$ & $0 \cdot 002$ & $0 \cdot 07$ & $0 \cdot 07$ & $0 \cdot 07$ & $0 \cdot 08$ & $0 \cdot 007$ & NS & NS \\
\hline & $0 \cdot 09$ & $0 \cdot 11$ & $0 \cdot 17$ & $0 \cdot 022$ & $0 \cdot 006$ & $0 \cdot 12$ & $0 \cdot 13$ & $0 \cdot 13$ & $0 \cdot 12$ & $0 \cdot 026$ & NS & NS \\
\hline \multicolumn{13}{|l|}{ Isobutyrate + isovalerate } \\
\hline Total VFA & $4 \cdot 6$ & $4 \cdot 7$ & $5 \cdot 6$ & $0 \cdot 16$ & $<0 \cdot 001$ & $4 \cdot 9$ & $5 \cdot 1$ & $5 \cdot 0$ & $4 \cdot 9$ & $0 \cdot 18$ & NS & NS \\
\hline Acetate:propionate (M:M) & $2 \cdot 5$ & $3 \cdot 1$ & $2 \cdot 7$ & $0 \cdot 11$ & $0 \cdot 001$ & $2 \cdot 7$ & $2 \cdot 8$ & $2 \cdot 8$ & $2 \cdot 7$ & $0 \cdot 12$ & NS & NS \\
\hline \multicolumn{13}{|l|}{ VFA (mM:mM) } \\
\hline Acetate & 0.61 & 0.63 & $0 \cdot 60$ & $0 \cdot 016$ & $0 \cdot 046$ & 0.61 & $0 \cdot 62$ & 0.62 & $0 \cdot 60$ & $0 \cdot 018$ & NS & NS \\
\hline Propionate & $0 \cdot 24$ & $0 \cdot 21$ & $0 \cdot 23$ & 0.009 & $0 \cdot 004$ & $0 \cdot 23$ & $0 \cdot 22$ & $0 \cdot 22$ & $0 \cdot 23$ & $0 \cdot 010$ & NS & NS \\
\hline Butyrate & $0 \cdot 11$ & $0 \cdot 13$ & $0 \cdot 12$ & 0.008 & NS & $0 \cdot 12$ & $0 \cdot 12$ & $0 \cdot 12$ & $0 \cdot 12$ & 0.009 & NS & NS \\
\hline \multirow[t]{2}{*}{ Valerate } & $0 \cdot 01$ & $0 \cdot 01$ & $0 \cdot 02$ & $0 \cdot 001$ & $0 \cdot 039$ & $0 \cdot 01$ & $0 \cdot 01$ & $0 \cdot 02$ & $0 \cdot 02$ & $0 \cdot 001$ & NS & NS \\
\hline & $0 \cdot 02$ & $0 \cdot 02$ & 0.03 & $0 \cdot 004$ & NS & 0.03 & $0 \cdot 02$ & $0 \cdot 03$ & 0.03 & $0 \cdot 004$ & NS & NS \\
\hline
\end{tabular}

* $I$, inoculum effect; $T$, treatment effect; $I \times T$, inoculum $\times$ treatment interaction; VFA, volatile fatty acid; IVD, in vitro dry matter disappearance; S.E.D., standard error of difference. 
Table 3. Influence of different S. cerevisiae products (inactivated yeast extract, IY; live yeast cells, YC; IY at 250 and 500 mg product per litre of incubation medium, IY250 and IY500, respectively) on in vitro fermentation of high-concentrate TMR (24 h, DM basis)

\begin{tabular}{|c|c|c|c|c|c|c|c|c|c|c|c|c|}
\hline & \multicolumn{3}{|c|}{ Inoculum $n=8$} & \multirow[b]{2}{*}{ S.E.D. } & \multirow[b]{2}{*}{$P$ value $I$} & \multicolumn{4}{|c|}{ Treatment $n=6$} & \multirow[b]{2}{*}{ S.E.D. } & \multirow[b]{2}{*}{$P$ value $T$} & \multirow[b]{2}{*}{$P$ value $I \times T$} \\
\hline & Control & IY & YC & & & Control & IY250 & IY500 & YC & & & \\
\hline $\mathrm{pH}$ & $6 \cdot 7$ & $6 \cdot 7$ & $6 \cdot 7$ & $0 \cdot 01$ & $0 \cdot 033$ & $6 \cdot 7$ & $6 \cdot 7$ & $6 \cdot 7$ & $6 \cdot 7$ & $0 \cdot 01$ & NS & NS \\
\hline IVD (g/g) & $0 \cdot 78$ & $0 \cdot 78$ & $0 \cdot 79$ & $0 \cdot 007$ & NS & $0 \cdot 78$ & $0 \cdot 78$ & $0 \cdot 78$ & $0 \cdot 79$ & $0 \cdot 008$ & NS & NS \\
\hline Total gas $(\mathrm{ml} / \mathrm{g})$ & 152 & 159 & 169 & $3 \cdot 1$ & $<0 \cdot 001$ & 160 & 157 & 161 & 162 & $3 \cdot 6$ & NS & NS \\
\hline $\mathrm{CH}_{4}(\mathrm{mM} / \mathrm{g}$ DM incubated) & $1 \cdot 6$ & $1 \cdot 7$ & $1 \cdot 8$ & $0 \cdot 03$ & $<0 \cdot 001$ & $1 \cdot 7$ & $1 \cdot 7$ & $1 \cdot 7$ & $1 \cdot 7$ & $0 \cdot 03$ & NS & NS \\
\hline $\mathrm{CH}_{4}(\mathrm{mM} / \mathrm{g} \mathrm{DM}$ digested $)$ & $2 \cdot 1$ & $2 \cdot 2$ & $2 \cdot 3$ & $0 \cdot 05$ & $0 \cdot 006$ & $2 \cdot 1$ & $2 \cdot 2$ & $2 \cdot 2$ & $2 \cdot 2$ & $0 \cdot 06$ & NS & NS \\
\hline $\mathrm{CH}_{4}(\mathrm{mM} / \mathrm{M}$ gas $)$ & 230 & 233 & 235 & $5 \cdot 6$ & NS & 231 & 237 & 232 & 230 & $6 \cdot 5$ & NS & NS \\
\hline $\mathrm{NH}_{3}-\mathrm{N}(\mathrm{mg} / \mathrm{l})$ & 406 & 380 & 431 & $24 \cdot 3$ & NS & 391 & 412 & 423 & 397 & $28 \cdot 0$ & NS & NS \\
\hline L-lactate (mg/l) & $8 \cdot 4$ & $9 \cdot 3$ & $11 \cdot 0$ & $0 \cdot 97$ & $0 \cdot 055$ & $8 \cdot 8$ & $9 \cdot 9$ & $9 \cdot 9$ & $9 \cdot 7$ & $1 \cdot 12$ & NS & NS \\
\hline \multicolumn{13}{|l|}{ VFA (mmol/g) } \\
\hline Acetate & $3 \cdot 14$ & $3 \cdot 18$ & $3 \cdot 38$ & $0 \cdot 098$ & NS & $3 \cdot 31$ & $3 \cdot 23$ & $3 \cdot 30$ & $3 \cdot 24$ & $0 \cdot 113$ & NS & NS \\
\hline Propionate & $1 \cdot 02$ & $0 \cdot 94$ & $1 \cdot 08$ & $0 \cdot 032$ & $0 \cdot 003$ & $1 \cdot 01$ & $1 \cdot 01$ & $1 \cdot 03$ & $1 \cdot 02$ & 0.036 & NS & NS \\
\hline Butyrate & $0 \cdot 71$ & $0 \cdot 72$ & $0 \cdot 72$ & $0 \cdot 048$ & NS & $0 \cdot 71$ & $0 \cdot 72$ & $0 \cdot 71$ & $0 \cdot 73$ & $0 \cdot 055$ & NS & NS \\
\hline \multirow[t]{2}{*}{ Valerate } & $0 \cdot 11$ & $0 \cdot 10$ & $0 \cdot 10$ & $0 \cdot 007$ & NS & $0 \cdot 10$ & $0 \cdot 10$ & $0 \cdot 11$ & $0 \cdot 10$ & $0 \cdot 007$ & NS & NS \\
\hline & $0 \cdot 21$ & $0 \cdot 21$ & $0 \cdot 22$ & $0 \cdot 022$ & NS & $0 \cdot 21$ & $0 \cdot 22$ & $0 \cdot 21$ & $0 \cdot 20$ & $0 \cdot 026$ & NS & NS \\
\hline \multicolumn{13}{|l|}{ Isobutyrate + isovalerate } \\
\hline Total VFA & $5 \cdot 2$ & $5 \cdot 2$ & $5 \cdot 5$ & $0 \cdot 02$ & NS & $5 \cdot 3$ & $5 \cdot 3$ & $5 \cdot 4$ & $5 \cdot 3$ & $0 \cdot 02$ & NS & NS \\
\hline Acetate:propionate (mol:mol) & $3 \cdot 1$ & $3 \cdot 4$ & $3 \cdot 1$ & $0 \cdot 13$ & NS & $3 \cdot 3$ & $3 \cdot 2$ & $3 \cdot 2$ & $3 \cdot 2$ & $0 \cdot 15$ & NS & NS \\
\hline \multicolumn{13}{|l|}{ VFA (mM:mM) } \\
\hline Acetate & $0 \cdot 60$ & $0 \cdot 62$ & $0 \cdot 61$ & $0 \cdot 008$ & NS & $0 \cdot 62$ & $0 \cdot 61$ & $0 \cdot 61$ & $0 \cdot 61$ & $0 \cdot 009$ & NS & NS \\
\hline Propionate & $0 \cdot 20$ & $0 \cdot 18$ & $0 \cdot 20$ & $0 \cdot 007$ & NS & $0 \cdot 19$ & $0 \cdot 19$ & $0 \cdot 19$ & $0 \cdot 20$ & $0 \cdot 008$ & NS & NS \\
\hline Butyrate & $0 \cdot 14$ & $0 \cdot 14$ & $0 \cdot 13$ & $0 \cdot 007$ & NS & $0 \cdot 13$ & $0 \cdot 14$ & $0 \cdot 13$ & $0 \cdot 14$ & $0 \cdot 008$ & NS & NS \\
\hline \multirow[t]{2}{*}{ Valerate } & $0 \cdot 02$ & $0 \cdot 02$ & $0 \cdot 02$ & $0 \cdot 001$ & NS & $0 \cdot 02$ & $0 \cdot 02$ & $0 \cdot 02$ & $0 \cdot 02$ & $0 \cdot 001$ & NS & NS \\
\hline & $0 \cdot 04$ & $0 \cdot 04$ & $0 \cdot 04$ & $0 \cdot 003$ & NS & $0 \cdot 04$ & $0 \cdot 04$ & $0 \cdot 04$ & $0 \cdot 04$ & $0 \cdot 003$ & NS & NS \\
\hline Isobutyrate + isovalerate & & & & & & & & & & & & \\
\hline
\end{tabular}

* I, inoculum effect; $T$, treatment effect; $I \times T$, inoculum $\times$ treatment interaction; VFA, volatile fatty acid; IVD, in vitro dry matter disappearance; S.E.D., standard error of difference. 
Table 5. Influence of different S. cerevisiae products (inactivated yeast extract, IY; live yeast cells, YC) on in vitro digestibility of diets ( $48 \mathrm{~h}, \mathrm{DM}$ basis)

\begin{tabular}{llllll}
\hline \hline & \multicolumn{3}{c}{ Treatment $n=3$} & & \\
\cline { 2 - 4 } & Control & IY & YC & S.E.D. & $P$ value \\
\hline High-forage TMR & & & & & \\
IVDMD (g/g)* & 0.82 & 0.81 & 0.81 & 0.012 & $\mathrm{NS}$ \\
$\quad$ IVNDFD (g/g) & 0.56 & 0.55 & 0.53 & 0.026 & $\mathrm{NS}$ \\
High-Concentrate & & & & & \\
TMR & & & & & \\
IVDMD (g/g) & 0.87 & 0.87 & 0.86 & 0.005 & $\mathrm{NS}$ \\
IVNDFD (g/g) & 0.47 & 0.49 & 0.45 & 0.026 & $\mathrm{NS}$ \\
\hline \hline
\end{tabular}

* IVDMD, in vitro dry matter digestibility; IVNDFD, in vitro neutral detergent fibre degradability; s.E.D., standard error of difference.

kinetics parameters were affected by inoculum, treatment or their interaction. Data regarding the digestibility at $48 \mathrm{~h}$ of diets are presented in Table 5 . Neither IVDMD nor IVNDFD for TMR were affected by the different yeast cells products used in the in vitro trial, showing values of IVDMD between 0.805 and 0.818 for high-forage TMR and between $0 \cdot 860$ and $0 \cdot 871 \mathrm{~g} / \mathrm{g}$ for high-concentrate diet, and values of IVNDFD between 0.530 and 0.561 for high-forage TMR and between 0.447 and $0.490 \mathrm{~g} / \mathrm{g}$ for high-concentrate TMR.

\section{DISCUSSION}

The current study was designed to test two different doses of inactivated yeast supplement against a live yeast product on in vitro ruminal fermentation of medium-high fibre and high concentrate ratios. Doses of yeast products used in the assays were calculated on the basis of the amounts administered to the animals according to the manufacturers ( $3 \cdot 5 \mathrm{~g}$ /day per sheep of Thepax $100 \mathrm{R}$ and $1.5 \mathrm{~g}$ /day per sheep of Yea-Sacc ${ }^{1026}$ ). It must be stressed that no effects of either inactivated or live yeasts were observed due to the direct addition of these products to batch cultures, with none of the diets used as fermentation substrate. Any significant differences observed in the present study were among the inocula used in the fermentation, obtained from animals that received control or supplemented diets for 10 days. This is an important observation and could explain the disparity of responses to live yeasts and yeast culture found in several in vitro studies reported in the literature. The current 
experiment was designed to test not only acute, immediate, responses to yeast additives but also the effects on ruminal fermentation when the additive was administered regularly. The fact that the direct addition of a single dose of yeast product to batch cultures (with 24-h or 144-h incubations) had no effect on in vitro ruminal fermentation, whereas some noticeable differences were observed among inocula from animals receiving no yeast or one of the yeast products tested, indicates that yeasts induce changes in the rumen microbial population, requiring some long-standing adaptation to and interaction with yeasts for changes in ruminal fermentation pattern to become apparent. In contrast, yeast would not induce prompt changes in the ruminal microbial population, and thus short-term shifts in fermentation pattern cannot be expected in response to yeast products. Thus, Koul et al. (1998) did not observe changes due to the addition of a single dose of autoclaved yeasts to the rumen of buffalo calves. However, the current results are consistent with those reported by Oeztuerk et al. (2005) and Oeztuerk (2009), who reported long-term effects (decline in $\mathrm{pH}$ and increase in ammonia concentration) of autoclaved and live yeast added to Rusitec fermenters, although the effects were more pronounced when live yeast culture was used. The adaptive effect could be mediated by a prebiotic effect of yeast cells or some heat labile components (Oeztuerk et al. 2005), which may derive from the microbial degradation of the yeast cells. The latter could partly explain the differences observed between live and inactivated yeasts.

With both diets, yeast live cells decreased the ruminal $\mathrm{pH}$ compared to control, whereas inactivated yeast had no effect. In all cases the $\mathrm{pH}$ values remained above $6 \cdot 5$, the physiological range of a healthy rumen. Inconsistent effects of $S$. cerevisiae on ruminal $\mathrm{pH}$ have been reported in numerous in vivo and in vitro studies. The current results are consistent with some of those observed by Lynch \& Martin (2002), where live cells decreased ruminal $\mathrm{pH}$ when alfalfa hay was incubated, with final values above 6.0. However, live yeast did not affect ruminal $\mathrm{pH}$ when a more concentrate substrate was fermented (Lynch \& Martin 2002). The current results are consistent with previous findings that adding inactivated yeast culture had no effect on $\mathrm{pH}$ values when TMR with variable forage to concentrate ratios (ranging from 0 4:0 6 to $0 \cdot 67: 0 \cdot 33$ ) were fermented (Piva et al. 1993; Enjalbert et al. 1999; Erasmus et al. 2005). In contrast, other authors have reported a slight rise in ruminal $\mathrm{pH}$ in response to the addition of a live yeast supplement to the diet (Nocek et al. 2002; Bach et al. 2007; Thrune et al. 2009). Guedes et al. (2008) observed that when maize silage was fermented, the effect of the yeast culture on $\mathrm{pH}$ was consistent with the changes observed in ruminal lactate concentration. Increasing activity of lactateutilizing bacteria and/or decreasing of activity of lactate-producing bacteria will cause a decrease in lactate concentration giving rise to higher $\mathrm{pH}$ values in the rumen. Decreased lactate concentration has been reported in response to the addition of live yeast when forage or concentrates were fermented (Lila et al. 2004). In the current study, lactate concentration was increased when live yeast (YC) was added to a highconcentrate diet, which agrees with results reported by Lynch \& Martin (2002) using ground maize as fermentation substrate. Therefore, these variations could be a consequence of the interaction between the S. cerevisiae and lactate-metabolizing bacteria, such as Streptococcus bovis, Megasphaera elsdenii or Selenomonas ruminantium, when competing for the utilization of sugars, regarding yeast live cells, or through the supply of growth factors (such as amino acids, peptides, vitamins and organic acids) in the case of yeast culture. Ruminal $\mathrm{NH}_{3}-\mathrm{N}$ concentration was not affected by inactivated or live yeast supplements to a high-concentrate ratio, which is consistent with other studies (Lila et al. 2004; Erasmus et al. 2005; Guedes et al. 2008) using different substrates in their experiments. However, with the high-fibre diet the addition of YC resulted in higher ammonia concentrations. The unexpected increases of lactate and $\mathrm{NH}_{3}-\mathrm{N}$ production observed upon the addition of yeast live cells could be due to the level of yeast inclusion used in the experiment, as suggested by Newbold et al. (1995), who concluded that greater outputs of fermentation end-products detected in the Rusitec fermenters supplemented with yeast additives could represent a response to increased substrate supply rather than a shift in the fermentation pattern.

Supplementation of the high-fibre diet with yeast additives had effects on total VFA production and VFA composition, in general with a slight increase when inactivated yeast culture was added, and a significantly greater increase in response to the addition of live yeast (YC) product. This result is consistent with the slight decline in the rumen $\mathrm{pH}$ discussed above, and with data obtained when yeast culture was added to maize silage (Guedes et al. 2008) or to a high forage diet (Enjalbert et al. 1999) or when YC were added to a hay plus concentrate diet (Lila et al. 2004). No effects on total VFA concentration were observed when yeast 
additives were used with the high-concentrate TMR, in agreement with other published data (Piva et al. 1993; Doreau \& Juoany 1998). The increase in the molar proportion of acetate observed when inactivated yeast culture was added to a high-forage TMR is also in agreement with results reported by Mutsvangwa et al. (1992) testing a yeast culture. Increased acetate to propionate ratios in response to IY supplementation occurred because acetate increased at the expense of propionate but, in general, acetate to propionate ratio measured in the batch cultures would be within the range of a good fibre digestion. The current results are in agreement with Lila et al. (2004), who also observed an increase in propionate molar proportion when live yeast was added to starchy substrates. The change in VFA concentration and/or molar proportion observed in the current experiment can be explained by modification of bacterial population in response to yeast supplementation. Acetate formation is mainly due to structural carbohydrate fermentation by cellulolytic bacteria, whereas the fermentation of non-structural carbohydrate by amylolytic bacteria leads to a relatively greater production of propionate. Microbial changes that occur within the rumen in response to $S$. cerevisiae addition to the diet may be increased (Newbold et al. 1996) or decreased (Mathieu et al. 1996) numbers of total viable bacteria, increased (Wiedmeier et al. 1987; El Hassan et al. 1996; Newbold et al. 1996), unchanged (Dawson et al. 1990; Erasmus et al. 1992; Yoon \& Stern 1996) or decreased (Mathieu et al. 1996) counts of cellulolytic bacteria, and no effects (Kumar et al. 1994; Yoon \& Stern 1996) on amylolytic bacteria. These reported trends towards an increased ratio of cellulolytic to amylolytic bacteria could therefore lead to a change in VFA production and an increased acetate:propionate ratio.

Neither diet considered in the current study had any effect on in vitro DM and NDF digestibility. A similar response in digestibility of bermudagrass hay was observed by Lynch \& Martin (2002) when both yeast culture and live cells were added, and by Carro et al. (1992) with the addition of yeast culture on 50 forage:50 concentrate ratio. With both TMRs used in the current study, total gas production increased when live yeast was added, in agreement with Lila et al. (2004), whereas the inactivated product had no effect on fermentation gas. Both fermentation gas and propionate production were increased when substrates were fermented in rumen fluid obtained from animals supplemented with YC, suggesting that propionate would derive from the succinate pathway explaining the higher total gas volume released, probably in the form of carbon dioxide (Wolin \& Miller 1988). As both gas production and substrate digestibility were increased with the high-forage diet when YC inoculum was used, fermentation efficiency (mg DM degraded/ $\mathrm{ml}$ gas production) was not affected. Methane production was increased in response to the addition of inactivated yeast and, to a greater extent, in response to YC. This increase is consistent with the higher acetate production, suggesting that fermentation may have been shifted to an acetogenic pathway.

The results obtained from $144 \mathrm{~h}$ incubations showed differences, only with the 0.6:0.4 forage:concentrate ratio, in the cumulative gas production at $24 \mathrm{~h}$ of incubation and in the average fermentation rate, which were greater with live yeast, although the asymptotic gas production was not affected. Dawson (1990) and Williams et al. (1991) suggested that ruminal micro-organisms could be stimulated by yeasts at initial stages of fermentation, but these effects would become negligible in the medium-term with longlasting fermentations.

\section{CONCLUSIONS}

Both inactivated and live yeast products tested in the trial may stimulate ruminal fermentation, although such an effect requires a regular administration of the product and some adaptation of the ruminal microbial population for the stimulatory effects to become apparent. Based on the current results, live yeasts would affect ruminal fermentation to a slightly greater extent than inactivated yeasts, but none of them showed immediate acute effects. On the other hand, effects of yeast on ruminal fermentation were diet-dependent, being more noticeable with a high-fibre substrate, and less evident with a high concentrate diet.

This work was funded by the Regione Piemonte, Assessorato Qualità, Ambiente e Agricoltura (Project Rep. n. 13428), the Ministero dell'Università e della Ricerca, PRIN (Project n. 2007P8JMWJ_002) and Junta de Castilla y León, Spain (Project n. GR158). Raúl Bodas has a JAE-Doc contract from the CSIC under the programme 'Junta para la Ampliación de Estudios'. All the authors contributed equally to the work described in this paper. Mention of trade names is for the benefit of the reader and does not constitute endorsement by the University of Turin, Italy, and of Leon, Spain, over other products not mentioned. 


\section{REFERENCES}

ANAdón, A. (2006). The EU ban of antibiotics as feed additives (2006): alternatives and consumers safety. Journal of Veterinary Pharmacology and Therapeutics 29 (Suppl. 1), 41-44.

Ankom Technology Corporation (1997). Operator's Manual: Ankom 200/220 Fiber Analyzer. Fairport, NY: Ankom Technology Corporation.

Arcos-García, J. L., Castrejón, F. A., Mendoza, G. D. \& PérezGavilán, E.P. (2000). Effect of two commercial yeast cultures with Saccharomyces cerevisiae on ruminal fermentation and digestion in sheep fed sugar cane tops. Livestock Production Science 63, 153-157.

Association of Official Analytical Chemists (2000). Official Methods of Analysis. 17th edn. Washington, DC: AOAC.

Bach, A., Iglesias, C. \& Devant, M. (2007). Daily rumen pH pattern of loose-housed dairy cattle as affected by feeding pattern and live yeast supplementation. Animal Feed Science and Technology 136, 146-153.

Callaway, E.S. \& Martin, S.A. (1997). Effects of a Saccharomyces cerevisiae culture on ruminal bacteria that utilize lactate and digest cellulose. Journal of Dairy Science 80, 2035-2044.

Carro, M. D., Lebzien, P. \& Rohr, K. (1992). Influence of yeast culture on the in vitro fermentation (Rusitec) of diets containing variable portions of concentrates. Animal Feed Science and Technology 37, 209-220.

Chaucheyras-Durand, F., Fonty, G., Bertin, G., Salmon, J. M. \& Gouet, P. (1996). Effects of a strain of Saccharomyces cerevisiae (Levucell SC), a microbial additive for ruminants, on lactate metabolism in vitro. Canadian Journal of Microbiology 42, 927-933.

Chaucheyras-Durand, F., Walker, N. D. \& Bach, A. (2008). Effects of active dry yeasts on the rumen microbial ecosystem: past, present and future. Animal Feed Science and Technology 145, 5-26.

Chiquette, J. (1995). Saccharomyces cerevisiae and Aspergillus oryzae, used alone or in combination, as a feed supplement for beef and dairy cattle. Canadian Journal of Animal Science 75, 405-415.

Council of the European Communities (CEC) (1986). Council Directive 86/609/EEC of 24 November 1986 on the approximation of laws, regulations and administrative provisions of the member states regarding the protection of animals used for experimental and other scientific purposes. Official Journal of the European Communities L358, $1-28$.

Dann, H. M., Drackley, J. R., McCoy, G. C., Hutjens, M. F. \& Garrett, J.E. (2000). Effects of yeast culture (Saccharomyces cerevisiae) on prepartum intake and postpartum intake and milk production of Jersey cows. Journal of Dairy Science 83, 123-127.

Dawson, K.A. (1990). Designing the yeast culture of tomorrow-mode of action of yeast culture for ruminants and non-ruminants. In Biotechnology in the Feed Industry, Proceedings of the Alltech's VIth Annual Symposium (Ed. T. P. Lynne), pp. 59-78. Lexington, KY: Alltech Technical Publications.
Dawson, K. A., Newman, K. E. \& Boling, J. A. (1990). Effects of microbial supplements containing yeast and lactobacilli on roughage-fed ruminal microbial activities. Journal of Animal Science 68, 3392-3398.

Doreau, M. \& Jouany, J.P. (1998). Effect of a Saccharomyces cerevisiae culture on nutrient digestion in lactating dairy cows. Journal of Dairy Science 81, 3214 3221.

El Hassan, S. M., Newbold, C. J., Edwards, I. E., Topps, J. H. \& Wallace, J. R. (1996). Effect of yeast culture on rumen fermentation, microbial protein flow from the rumen and live-weight gain in bulls given high cereal diets. Animal Science 62, 43-48.

Enjalbert, F., Garrett, J. E., Moncoulon, R., Bayourthe, C. \& Chicoteau, P. (1999). Effects of yeast culture (Saccharomyces cerevisiae) on ruminal digestion in nonlactating dairy cows. Animal Feed Science and Technology 76, 195-206.

Erasmus, L. J., Botha, P. M. \& Kistner, A. (1992). Effect of yeast culture supplement on production, rumen fermentation, and duodenal nitrogen flow in dairy cows. Journal of Dairy Science 75, 3056-3065.

Erasmus, L. J., Robinson, P. H., Ahmadi, A., Hinders, R. \& Garrett, J.E. (2005). Influence of prepartum and postpartum supplementation of a yeast culture and monensin, or both, on ruminal fermentation and performance of multiparous dairy cows. Animal Feed Science and Technology 122, 219-239.

Fortina, R., Battaglini, L. M., Bianchi, M., Mimosi, A., Opsi, F., Tassone, S. \& Rovera, A. (2009). Perché i lieviti inattivati nelle razioni dei vitelloni. Informatore Zootecnico 11, 79-83.

France, J., Dijkstra, J., Dhanoa, M. S., López, S. \& Bannink, A. (2000). Estimating the extent of degradation of ruminant feeds from a description of their gas production profiles observed in vitro: derivation of models and other mathematical considerations. British Journal of Nutrition, Cambridge 83, 143-150.

Guedes, C. M., Gonçalves, D., Rodrigues, M. A. M. \& Dias-DaSiLva, A. (2008). Effects of a Saccharomyces cerevisiae yeast on ruminal fermentation and fibre degradation of maize silages in cows. Animal Feed Science and Technology 145, 27-40.

Harris, B. \& WebB, D. W. (1990). The effect of feeding a concentrate yeast culture to lactating dairy cows. Journal of Dairy Science 73 (Suppl. 1), 226 (Abstract).

Harrison, G. A., Hemken, R. W., Dawson, K. A., Harmon, R. J. \& BARKER, K.B. (1988). Influence of addition of yeast culture supplement to diets of lactating cows on ruminal fermentation and microbial populations. Journal of Dairy Science 71, 2967-2975.

Hession, A. O., Tung, R. S., Kreck, E. M. \& Kung, L. (1992). Effect of adding live yeast culture on in vitro ruminal fermentation. Journal of Animal Science 70 (Suppl. 1), 309 (Abstract).

Kamalamma, Krishnamoorthy, U. \& KrishnapPa, P. (1996). Effect of feeding yeast culture (Yea-Sacc ${ }^{1026}$ ) on rumen fermentation in vitro and production performance in crossbred dairy cows. Animal Feed Science and Technology 57, 247-256. 
Koul, V., Kumar, U., Sareen, V. K. \& Singh, S. (1998). Mode of action of yeast culture (YEA-SACC 1026) for stimulation of rumen fermentation in buffalo calves. Journal of the Science of Food and Agriculture 77, 407-413.

Kumar, U., Sareen, V.K. \& Singh, S. (1994). Effect of Saccharomyces cerevisiae yeast culture supplement on ruminal metabolism in buffalo calves given a high concentrate diet. Animal Production 59, 209-215.

Kung, L., Kreck, E.M., Tung, R.S., Hession, A. O., Shepherd, A. C., Cohen, M. A., Swain, H. E. \& Leelde, J. A. (1997). Effects of a live yeast culture and enzymes on in vitro ruminal fermentation and milk production of dairy cows. Journal of Dairy Science 80, 2045-2051.

Lila, Z. A., Mohammed, N., Yasui, T., Kurokawa, Y., Kanda, S. \& ITABASHI, H. (2004). Effects of a twin strain of Saccharomyces cerevisiae live cells on mixed ruminal microorganism fermentation in vitro. Journal of Animal Science 82, 1847-1854.

LINN, J. \& RAETH-KNIGHT, M. (2006). Yeast in dairy cattle diets. In Proceedings of the 2006 Four State Dairy Nutrition and Management Conference, pp. 85-90. Ames, IA: lowa State University, MWPS.

LYNCH, H. A. \& MARTIN, S. A. (2002). Effects of Saccharomyces cerevisiae culture and Saccharomyces cerevisiae live cells on in vitro mixed ruminal microorganism fermentation. Journal of Dairy Science 85, 2603-2608.

López, S., Dhanoa, M. S., Dijkstra, J., Bannink, A., Kebreab, E. \& FrANCE, J. (2007). Some methodological and analytical considerations regarding application of the gas production technique. Animal Feed Science and Technology 135, 139-156.

Martin, S. A., Nisbet, D. J. \& Dean, R. G. (1989). Influence of a commercial yeast supplement on the in vitro ruminal fermentation. Nutrition Reports International 40, 395-403.

Mathieu, F., Jouany, J. P., Sénaud, J., Bohatier, J., Bertin, G. \& MerCIER, M. (1996). The effect of Saccharomyces cerevisiae and Aspergillus oryzae on fermentations in the rumen of faunated and defaunated sheep: protozoal and probiotic interactions. Reproduction Nutrition Development 36, 271-287.

Mendoza, M. G. D., Ricalde, V.R., Esparza, B. H. \& VelazQuez, T.L. (1995). Technical note: effects of two yeast culture with Saccharomyces cerevisiae on ruminal neutral detergent fiber degradability. Investigación Agraria: Producción y Sanidad Animales 10, 33-38.

Menke, K.H. \& Steingass, H. (1988). Estimation of the energetic feed value obtained from chemical analysis and in vitro gas production using rumen fluid. Animal Research and Development 28, 7-55.

Mimosi, A., Fortina, R., Battaglini, L. M., Bianchi, M. \& Rovera, A. (2008). Aumenta la qualità del latte con i lieviti. Informatore Zootecnico 8, 72-74.

Mutsvangwa, T., EDWARDS, I. E., Topps, J.H. \& Paterson, G. F. M. (1992). The effect of dietary inclusion of yeast culture (Yea-sacc) on patterns of rumen fermentation, food intake and growth of intensively fed bulls. Animal Production 55, 35-41.
Newbold, C. J., Wallace, R. J., Chen, X. B. \& Mclntosh, F. M. (1995). Different strains of Saccaromyces cerevisiae differ in their effects on ruminal bacterial numbers in vitro and in sheep. Journal of Animal Science 73, 1811-1818.

Newbold, C. J., Wallace, R. J. \& Mcintosh, F. M. (1996). Mode of action of the yeast Saccharomyces cerevisiae as a feed additive for ruminants. British Journal of Nutrition, Cambridge 76, 249-261.

Nocek, J. E., Kautz, W.P., Leedle, J.A. Z. \& Allman, J. G. (2002). Ruminal supplementation of direct-fed microbials on diurnal $\mathrm{pH}$ variation and in situ digestion in dairy cattle. Journal of Dairy Science 85, 429-433.

Nocek, J. E., Kautz, W. P., Leedle, J. A. Z. \& Block, E. (2003). Direct-fed microbial supplementation on the performance of dairy cattle during the transition period. Journal of Dairy Science 86, 331-335.

Oeztuerk, H. (2009). Effects of live and autoclaved yeast cultures on ruminal fermentation in vitro. Journal of Animal and Feed Sciences 18, 142-150.

Oeztuerk, H., Schroeder, B., Beyerbach, M. \& Breves, G. (2005). Influence of living and autoclaved yeasts of Saccharomyces boulardii on in vitro ruminal microbial metabolism. Journal of Dairy Science 88, 2594-2600.

Ottenstein, D. M. \& Bartley, D. A. (1971). Improved gas chromatography separation of free acid C2-C5 in dilute solution. Analytical Chemistry 43, 952-955.

Piva, G., Belladonna, S., Fusconi, G. \& Sicbaldi, F. (1993). Effects of yeast on dairy cow performance, ruminal fermentation, blood components, and milk manufacturing properties. Journal of Dairy Science 76, 2717-2722.

Robinson, P. H., Mathews, M. C. \& Fadel, J. G. (1999). Influence of storage time and temperature on in vitro digestion of neutral detergent fibre at $48 \mathrm{~h}$, and comparison to $48 \mathrm{~h}$ in sacco neutral detergent fibre digestion. Animal Feed Science and Technology 80, 257-266.

TAYLOR, K. A. C. C. (1996). A simple colorimetric assay for muramic acid and lactic acid. Applied Biochemistry and Biotechnology 56, 49-58.

Theodorou, M.K., Williams, B.A., Dhanoa, M.S., McAllan, A. B. \& France, J. (1994). A simple gas production method using a pressure transducer to determine the fermentation kinetics of ruminant feeds. Animal Feed Science and Technology 48, 185-197.

Thrune, M., Bach, A., Ruiz-Moreno, M., Stern, M. D. \& LINN, J. G. (2009). Effects of Saccharomyces cerevisiae on ruminal $\mathrm{pH}$ and microbial fermentation in dairy cows. Yeast supplementation on rumen fermentation. Livestock Science 124, 261-265.

Van Soest, P. J., Robertson, J. B. \& Lewis, B. A. (1991). Methods of dietary fiber, neutral detergent fiber and nonpolysaccharides in relation to animal nutrition. Journal of Dairy Science 74, 3583-3597.

WallaCE, R. J. (1994). Ruminal microbiology, biotechnology and ruminant nutrition: progress and problems. Journal of Animal Science 72, 2992-3003.

Wallace, R. J. \& Newbold, C. J. (1993). Rumen fermentation and its manipulation: the development of yeast culture as feed additives. In Biotechnology in the Feed Industry, 
Alltech's IXth annual symposium (Ed. T.P. Lyons), pp. 173-192. Nicholasville, KY: Alltech Technical Publications.

Weatherburn, M.W. (1967). Phenol-hypochlorite reaction for determination of ammonia. Analytical Chemistry 39, 971-974.

Wiedmeier, R. D., Arambel, M. J. \& Walters, J. L. (1987). Effect of yeast culture and Aspergillus oryzae fermentation extract on ruminal characteristics and nutrient digestibility. Journal of Dairy Science 70, 2063-2068.

Williams, P.E., Tait, C. A., InNes, G.M. \& Newbold, C.J. (1991). Effects of the inclusion of yeast culture (Saccharomyces cerevisiae plus growth medium) in the diet of dairy cows on milk yield and forage degradation and fermentations patterns in the rumen of steers. Journal of Animal Science 69, 3016-3026.

Wolin, M.J. \& Miller, T.L. (1988). Microbe-microbe interactions. In The Rumen Microbial Ecosystem (Ed. P. J. Hobson), pp. 343-359. London, UK: Elsevier Applied Science.

YOON, I. K. \& STERN, M. D. (1996). Effects of Saccharomyces cerevisiae and Aspergillus oryzae cultures on ruminal fermentation in dairy cows. Journal of Dairy Science 79, 411-417.

Zeleñák, I., JalČ, D., KMET, V. \& SiROKA, P. (1994). Influence of diet and yeast supplement on in vitro ruminal characteristics. Animal Feed Science and Technology 49, 211-221. 